\title{
Assensus
}

Revista Assensus Vol 2, Núm 3

Septiembre - Diciembre 2017

ISSN 2619-3884

Recepción: Octubre 05 de 2016

Aceptación: Abril 12 de 2017

Publicación: Septiembre 01 de 2017

\section{Educação Superior em cena: percurso acadêmico e resultados da graduação.}

Educación Superior en escena: Recorrido académico y resultados de la graduación

Higher education on stage: Academic journey and results of graduation.

\section{Vera Lucía Felicetti}

Centro Universitario La Salle - Canoas - Brasil vera.felicetti@unilasalle.edu.br 


\section{Assensus}

\section{Resumen}

Este artículo (conferencia) empieza con una retrospectiva histórica sobre el comprometimiento del estudiante con su aprendizaje en la trayectoria académico, teniendo en cuenta que este tema fue el núcleo de un primer proyecto, que seguido por otros dos, involucran el tema de la Educación Superior. Posteriormente se presentan algunos de los resultados de los tres proyectos de investigación que se centran en el acceso, en la trayectoria en la universidad, y también en los resultados de la graduación. El acceso está relacionado con las características iniciales de los estudiantes al entrar en la universidad; en la trayectoria se identifican factores que intervienen en la permanencia o no del estudiante en la universidad y finalmente se presentan los beneficios de la graduación. Los tres proyectos de investigación, se desarrollaron con la participación de egresados de educación superior de tres universidades sin fines lucrativos del Sur de Brasil, correspondiendo cada proyecto con una universidad. El criterio de selección de sujetos participantes en la investigación, fue haber iniciado su formación en la Institución de Educación Superior, en el año 2005 y haberse graduado. En el primer proyecto la invitación se extendió a los estudiantes que eran becarios del Programa Universidad para Todos (ProUni); el segundo con beca o sin ella para carreras cómo letras, las matemáticas, biología y otras para la docencia; el tercero proyecto incluyó a todos los estudiantes que ingresaron a la universidad independientemente de e tener o no la beca.

La metodología utilizada en el primer proyecto fue mixta y en los dos siguientes cuantitativa. Los tres proyectos tienen objetivos similares, pero coherentes con los perfiles de participantes. El objetivo general del primer proyecto fue analizar el compromiso de alumnos ProUni, con su aprendizaje, y el impacto que este perfil académico puede desencadenar la universidad y en la sociedad. El segundo y tercer proyectos están orientados al estudio de las características de acceso, trayectoria y resultados académicos de los estudiantes egresados que tenían beca (ProUni), en comparación con quienes no la tenían. El diseño, la revisión y mejora del instrumento de investigación también fue un objetivo en los proyectos. Como resultado de ello, debido al alcance de este artículo, sólo se presentan algunos avances relacionados con a la trayectoria académica y con los resultados de la formación. El primer proyecto ratifica el comprometimiento del estudiante ProUni como factor importante para superar las dificultades encontradas en contexto académico, y que a su vez se refleja en posibilidades de empleo y satisfacción laboral.

En el segundo proyecto, las dificultades en la trayectoria académica son evidentes, y están relacionadas con la ausencia de requisitos previos, aspectos materiales, interrelaciónales, que no mostraron diferencia significativa entre los estudiantes becados y los que no lo eran. Desde el anterior hallazgo se indica que los graduados que no eran ProUni pueden haber enfrentado las mismas dificultades que a los que tenían la beca del programa. La relación entre la satisfacción con la formación, con el trabajo logrado y con las opciones de elección del curso, resulta ser más fuerte la posibilidad de elegir los cursos por afinidad / habilidades a la perspectiva de elección por factores económicos de ambos grupos. Entre los resultados que se destacan en el tercer proyecto, las dificultades 
que se presentaran durante la trayectoria académica muestran similitud entre los estudiantes becados a través de ProUni, como para los que no lo fueron. En cuanto al desempeño laboral en relación con la formación, emergen las variables: satisfacción en el trabajo, con la graduación, con el desarrollo de habilidades, el crecimiento personal y otros. Estos resultados parecen indicar que el grado académico proporciona igualdad de oportunidades en el mercado laboral, es decir que para los graduados del Programa Universidad para Todos son dadas condiciones necesarias para competir en la obtención de nuevos y mejores perspectivas de vida. En cuanto a la mejora del instrumento de la encuesta, fue hecho análisis factorial aplicado en cada instrumento, destacando que las encuestas registraron un gran avance en la consistencia interna de cada grupo de preguntas de acuerdo con Alpha de Cronbach. Esto sostiene la coherente validación para su aplicación en el cuarto proyecto de investigación que ya está en marcha. Los resultados también indican la necesidad de una investigación más amplia, con la participación de diferentes universidades y regiones.

\section{Resumo}

Este artigo (conferência) começa com uma retrospectiva histórica sobre o compromisso da aprendizagem dos alunos na carreira acadêmica, considerando que esta questão foi o núcleo de um primeiro projeto, seguido por dois outros, envolvem a questão do Ensino Superior. Mais tarde alguns dos resultados de projectos de investigação de três que incidem sobre o acesso, no caminho da universidade, e também no ranking resultados são apresentados. 0 acesso está relacionada com as características iniciais dos alunos que entram na universidade; nos fatores de caminhos envolvidos na retenção ou estudante na faculdade e, finalmente, a benefícios presente de formatura que são identificados. Os três projetos de pesquisa foram desenvolvidos com a participação de diplomados do ensino superior de três universidades sem fins lucrativos sul do Brasil, cada um correspondente a um projeto de universidade. Os critérios para seleção dos sujeitos que participam da pesquisa, era para ter começado o treinamento na Instituição de Ensino Superior, em 2005 e formou-se. No primeiro projeto, o convite foi estendido aos estudantes que estagiaram na Programa Universidade para Todos (ProUni); o segundo com bolsa ou sem correndo como letras, matemática, biologia e outra para o ensino; o terceiro projeto incluiu todos os estudantes que entraram faculdade e independentemente de haver ou não conceder.

A metodologia utilizada no primeiro projeto foi misturado e a seguinte quantitativa ambos. Os três projetos têm objetivos semelhantes, mas de acordo com os perfis dos participantes. O objectivo global do primeiro projeto foi analisar as autorizações estudantes do ProUni com sua aprendizagem, bem como o impacto deste perfil acadêmico pode desencadear a universidade ea sociedade. 0 segundo e terceiro projectos destinam-se a estudar as características de acesso, carreira e desempenho acadêmico dos estudantes que tinham graduados bolsa 


\section{Assensus}

de estudos (ProUni), em comparação com aqueles que não o fez. Elaboração, revisão e melhoria dos instrumentos de pesquisa também foi um alvo nos projetos. Como um resultado disso, por causa do âmbito deste artigo, apenas algumas relacionadas com o fundo académico e os resultados dos avanços de formação são apresentados. 0 primeiro projeto confirma o compromisso do aluno ProUni como um fator importante para superar as dificuldades encontradas no contexto acadêmico, e que por sua vez se reflete em oportunidades de emprego e satisfação no trabalho.

No segundo projeto, as dificuldades na carreira acadêmica são óbvias, e estão relacionados com a ausência de pré-requisitos, os aspectos relevantes, interrelacional, que mostraram não haver diferença significativa entre bolsistas e aqueles que não foram. Do exposto encontrando indica que os graduados que não eram ProUni pode ter enfrentado as mesmas dificuldades que aqueles que tinham o programa de bolsas. A relação entre a satisfação com a formação, com o realizado e com as opções de trabalho do curso escolha, acaba por ser mais fortes os cursos escolha de afinidade / competências para a perspectiva de escolha por factores económicos de ambos os grupos. Entre os resultados destacados no terceiro projecto, as dificuldades apresentadas durante o acadêmico registro mostra semelhança entre bolsistas através ProUni, como para aqueles que não foram. Quanto ao desempenho de trabalho em relação à formação, emergir variáveis: satisfação no trabalho, com graduação, com o desenvolvimento de habilidades, crescimento pessoal e outros. Estes resultados sugerem que o grau proporciona igualdade de oportunidades no mercado de trabalho, ou seja, para os graduados do Programa Universidade para Todos são dados necessários para competir na obtenção de novos e melhores condições de vida. Como para melhorar a instrumento de pesquisa que foi feita análise fatorial aplicada em cada instrumento, observando que as pesquisas registrou um avanço na consistência interna de cada cluster de acordo com Cronbach Alpha. Isto apoia a validação consistente para aplicação na quarta projeto de pesquisa que já está em andamento. Os resultados também indicam a necessidade de uma investigação mais aprofundada, com a participação de diferentes universidades e regiões.

\section{Abstract}

This article (conference) begins with a historical retrospective about the student's commitment to his / her academic learning, taking into account that this topic was the nucleus of a first project, followed by two others, involving the topic of Higher Education. Subsequently, some of the results of the three research projects that focus on access, on the path in the university, and also on the results of graduation are presented. Access is related to the initial characteristics of students upon entering university; In the trajectory are identified factors that intervene in the student's stay or not in the university and finally the benefits of graduation are presented. The three research projects were developed with the participation of higher education graduates from three non-profit universities in the South of Brazil, each project corresponding to a university. The criterion of selection of 


\section{Assensus}

subjects participating in the research was to have started their training at the Institution of Higher Education in 2005 and to have graduated. In the first project the invitation was extended to students who were scholarship holders of the University for All Program (ProUni); The second with or without a scholarship for careers such as letters, mathematics, biology and others for teaching; The third project included all students who entered the university regardless of whether or not they had the scholarship.

The methodology used in the first project was mixed and in the next two quantitative. The three projects have similar objectives, but are consistent with the profiles of participants. The overall objective of the first project was to analyze the commitment of ProUni students, with their learning, and the impact that this academic profile can unleash on the university and in society. The second and third projects are oriented to the study of the characteristics of access, trajectory and academic results of the graduated students that had scholarship (ProUni), in comparison with those who did not have it. The design, review and improvement of the research instrument was also an objective in the projects. As a result, due to the scope of this article, there are only some advances related to the academic trajectory and the results of the training. The first project ratifies the commitment of the ProUni student as an important factor to overcome the difficulties found in academic context, which in turn is reflected in the possibilities of employment and job satisfaction.

In the second project, difficulties in the academic trajectory are evident, and are related to the absence of prerequisites, material aspects, interrelationships, which did not show a significant difference between the scholarship students and those who were not. The previous finding indicates that graduates who were not ProUni may have faced the same difficulties as those who had the fellowship program. The relationship between satisfaction with training, the work achieved and the choice of the course, makes it possible to choose the courses by affinity / abilities to the perspective of choice by economic factors of both groups. Among the results highlighted in the third project, the difficulties presented during the academic trajectory show similarity among the scholarship students through ProUni, as for those who were not. Regarding job performance in relation to training, the following variables emerge: job satisfaction, graduation, skill development, personal growth and others. These results seem to indicate that the academic degree provides equal opportunities in the labor market, that is to say that for graduates of the University for All Program are given the necessary conditions to compete in obtaining new and better perspectives of life. Regarding the improvement of the instrument of the survey, factorial analysis was applied in each instrument, noting that the surveys registered a great advance in the internal consistency of each group of questions according to Cronbach's Alpha. This supports the consistent validation for its application in the fourth research project 


\section{Assensus}

that is already under way. The results also indicate the need for more extensive research, with the participation of different universities and regions.

\section{Palabras Clave}

Educación Superior. Trayectoria. Resultados de graduación. Comprometimiento.

\section{Keywords}

Higher Education.

Trajectory. Graduation results. Commitment.

\section{Palavras-chave}

Ensino Superior. Path. Resultados graduação. Comprometimiento.

\section{Introdução}

A Educação Superior tem, entre suas finalidades, de acordo com o Art. 43 da Lei de Diretrizes e Bases da Educação Nacional Brasileira, a de "formar diplomados nas diferentes áreas de conhecimento, aptos para a inserção em setores profissionais e para a participação no desenvolvimento da sociedade brasileira, e colaborar na sua formação contínua". (BRASIL, 2005, p.20). Observase que, atrelada à formação de diplomados aptos a atuarem profissionalmente em determinada área, está o desenvolvimento da sociedade. Este somente é possível quando há melhorias nas condições de vida da população, em especial em seus estratos mais baixos.

Sendo assim, a Educação Superior pode dar sua contribuição perante a sociedade tanto direta quanto indiretamente. Contribui diretamente quando torna as pessoas melhores como profissionais e como cidadãos e, indiretamente, quando colabora com a melhoria econômica e com a coesão social. Logo, esse nível de ensino tem papel preponderante na transformação social e econômica de um país (Felicetti, 2011). A transformação social somente ocorre quando pessoas de todos os estratos populacionais têm acesso à Educação Superior, bem como condições de nela permanecerem até a integralização da graduação, visto que o desenvolvimento de uma sociedade está associado ao nível educacional de sua população.

Com relação ao acesso à Educação Superior, o governo brasileiro institui programas com o objetivo de proporcionar o preenchimento de vagas ociosas e ampliar as já existentes em instituições públicas, tais como a Universidade Aberta do Brasil (UAB'); a consolidação e/ou implementação de centros de acessibilidade nas instituições federais ${ }^{2}$, a criação de institutos federais de Educação, Ciência e Tecnologia ${ }^{3}$, a Reestruturação e Expansão das Universidades

\footnotetext{
${ }^{1}$ A UAB consiste em uma rede nacional de Educação Superior a distância, que tem a participação do ensino superior público em parceria com estados e municípios. Oferece formação acadêmica para professores já no exercício da docência na Educação Básica e que ainda não são graduados.

${ }^{2} \mathrm{~A}$ implementação e/ou consolidação de centros de acessibilidade nas instituições federais tem por objetivo eliminar barreiras pedagógicas, atitudinais, de comunicação e de arquitetura, de modo a efetuar o acesso e a permanência de pessoas desabilitadas na Educação Superior. (BRASIL, 2008).

3 Os IFCE são instituições de Ensino Superior, básico e profissional, multicampi e pluricurriculares. Os IFCE oferecem educação tecnológica e profissional nas diferentes modalidades de ensino, tendo por base a união de conhecimentos técnicos e tecnológicos associados às práticas pedagógicas. (BRASIL, 2008).
} 


\section{Assensus}

Federais $\left(\right.$ REUNI $\left.^{4}\right)$ e, em instituições privadas e comunitárias ${ }^{5}$, o Fundo de Financiamento ao Estudante do Ensino Superior6 (FIES) e o Programa Universidade para Todos (ProUni). Este último foi criado em 2004 e estabilizado pela Lei $N^{\circ}$. 11.096, de 13 de janeiro de 2005. Destina-se à concessão de bolsas de estudo, integrais ou parciais, a brasileiros que ainda não concluíram a Educação Superior, para estudarem em instituições privadas ou comunitárias desse nível de ensino.

Tais programas de governo estão proporcionando, embora ainda haja inúmeras hierarquias e desigualdades nesse nível de ensino, o acesso de um novo perfil estudantil no espaço acadêmico. Isso proporcionou a diversificação a desse espaço quanto ao tipo étnico e renda. (Felicetti, 2011). Portanto, estudar o percurso acadêmico, bem como os resultados da formação na vida dos graduados, torna-se de suma importância.

Sabe-se que o acesso à Educação Superior foi, e ainda é, um desafio a ser transposto, em especial às pessoas oriundas de grupos tidos como em “desvantagens iniciais". Estas, segundo Felicetti e Morosini (2009, p.12) “[...] são aquelas que existem independentes do querer de cada um, tais como raça, sexo, idade, deficiências, família ou situação socioeconômica", ou seja, as características iniciais que muitos ingressantes trazem quando do ingresso na faculdade. No entanto, o acesso é apenas o início de um conjunto de fatores que envolvem, para muitos acadêmicos, além dos desafios inerentes à nova fase educacional, outros associados às suas características iniciais. Eis então que do acesso vem o contínuo, ou seja, o percurso acadêmico.

Diante de um "novo" perfil estudantil, o qual as Instituições de Educação Superior (IES) não têm como mudar (Felicetti, 2011), emerge a necessidade de um novo fazer na universidade. Um fazer capaz de não somente manter o estudante na faculdade, mas principalmente estimular o comprometimento do mesmo em relação ao seu fazer acadêmico. Por comprometimento, Felicetti e Morosini (2008) entendem ser constituído do que se faz e como se faz, estando assim relacionado aos objetivos do aluno, desencadeando o sentido de equilíbrio entre e querer e o fazer. Ao querer e ao fazer está, muitas vezes, associado o poder fazer. É aqui que entra a articulação entre o que a universidade deseja do aluno e o que este espera dela e enfrenta para nela permanecer. A primeira variável tem o papel de entender as necessidades dos seus alunos, proporcionando caminhos para que os mesmos alcancem os objetivos traçados a uma graduação, sem colocar em xeque a qualidade do ensino. A segunda variável diz respeito ao comprometimento do aluno no percurso acadêmico.

\footnotetext{
4 Foi instituído pelo Decreto n 6.096 , de 24 de abril de 2007. O REUNI é uma opção dada às universidades federais para a ampliação de vagas e o aprimoramento da qualidade do espaço universitário através de novos mecanismos de seleção de estudantes, novas articulações curriculares e novos percursos formativos. (BRASIL, 2007).

5 Instituições comunitárias de educação são definidas como instituições sem fins lucrativos.

6 Foi criado no ano de 1999 pelo Ministério da Educação brasileiro e substituiu o Programa de Crédito Educativo PCE/CREDUC. O FIES proporciona o financiamento de cursos de graduação para alunos matriculados em instituições privadas ou comunitárias sem condições de custear as mensalidades.
} 
Estar na Universidade e realizar um curso superior exigem do aluno uma postura comportamental de estudo diferente da exercida no nível de escolaridade anterior, visto que aqui há a necessidade de maior autonomia e dedicação aos estudos. Isso é devido não somente ao montante de conteúdos, mas também ao grau de dificuldade que Ihes impera mais complexo a cada etapa. Assim, "Toda aprendizagem e desenvolvimento requerem um investimento de tempo e esforço do aluno. O tempo é uma dimensão frequência. Esforço é uma dimensão de qualidade, no sentido de que alguns processos educacionais exigem mais esforços do que outros." (PACE, 1984, p. 4). A qualidade do esforço está relacionada com o desenvolvimento do estudante, logo alta qualidade de esforço gera alta qualidade de resultados (PACE, 1979, 1981, 1982, 1984). Para o autor, a educação envolve um processo e um produto. Este se caracteriza pelo conhecimento adquirido, valores, atitudes e características pessoais transformadas ou desenvolvidas. O processo corresponde aos caminhos ou métodos capazes de produzirem aprendizagem para o crescimento do produto.

Nesta direção, os estudos de Tyler (1949), voltados à teoria e prática curricular, sugeriram que os objetivos educacionais necessitam indicar conhecimentos, atitudes e habilidades que possam ajudar os alunos, vindo a satisfazer suas necessidades de maneira mais eficaz. Isto significa dizer que os objetivos educacionais não podem estar fechados em conteúdos ou propostas alheias à realidade dos estudantes, mas sim associados aos seus anseios e necessidades de modo que eles possam superar tanto os desafios inerentes como os impostos pela realidade de cada um. Logo, dar atenção a todos os intervenientes que perpassam o percurso acadêmico contribui para a permanência e sucesso dos estudantes na universidade.

Para Astin (1984), dispensar considerável energia estudando, participando ativamente do meio estudantil, interagindo assiduamente com seus colegas e professores faz com que os alunos tenham maiores progressos na aprendizagem. Portanto, "o envolvimento estudantil se refere ao montante de energia física e psicológica que o estudante dedica às experiências acadêmicas." (ASTIN, 1984, p.297). Novamente se percebe a necessidade de acompanhamento ao estar e fazer do estudante na universidade, de modo a perceber e melhor entender o todo que envolve o percurso acadêmico. Somente através desse entendimento, se pode assistir o estudante para que o mesmo tenha maior comprometimento e sucesso acadêmico.

Estudos voltados à integração social e acadêmica do estudante apontam com Tinto (1987), que pauta no papel que as IES têm para influenciar o desenvolvimento intelectual e social de seus alunos. Para o autor, "[...] as instituições e os estudantes seriam mais bem servidos se uma preocupação com a educação dos alunos, sua inserção social e crescimento intelectual, fosse o princípio orientador da ação institucional." (Tinto, 1987, p. 5). Tinto considera os aspectos relacionados à integração social e acadêmica na universidade, sendo estratégias para manter o aluno nela. Logo, as experiências individuais no interior da faculdade, tais como adaptação, dificuldade, incongruência e o isolamento descrevem um importante resultado interacional. Para ele, o sucesso da 


\section{Assensus}

permanência está no entusiasmo com que as IES se envolvem na promoção da interação e no desenvolvimento intelectual e social dos seus estudantes.

Chickering e Gamson (1987), com base em 50 anos de investigação sobre a maneira como os professores ensinam e como os estudantes aprendem, interagem e trabalham uns com os outros e como os alunos e professores falam uns com os outros, concluíram que: "Não há nem raiz, nem alicerce suficiente para melhorar a educação universitária sem o compromisso e ação de estudantes e professores. Eles são recursos preciosos dos quais a melhoria da educação universitária depende." (1987, p. 3). Na citação dos autores é possível perceber o comprometimento estudantil associado à ação, ao fazer, sendo ele também voltado ao corpo docente.

Pesquisas evidenciam que o aumento das chances de um acadêmico ter sucesso na Educação Superior está relacionado ao seu comprometimento. Isto é, associado ao que o estudante faz, como ele faz e como ele melhor aprende. (Kuh, et al., 1991; Kuh, et al., 2005). Para os autores,

Comprometimento tem dois componentes-chave. O primeiro é o montante de tempo e esforço que o estudante põe em seus estudos e outras atividades que conduzem para experiências e resultados que constituem o sucesso do estudante. O segundo é a forma como a instituição aloca seus recursos humanos e outros, organiza e possibilita serviços para incentivar os alunos a participarem e se beneficiarem de tais atividades. (KUH, et al., 2005, p. 4).

Os componentes evidenciados por Kuh e seus colegas (1991; 2005) referentes ao comprometimento vão ao encontro da teoria do envolvimento postulada por Astin (1984). Entretanto, segundo Harper e Quaye (2009, p.5), "Há uma diferença qualitativa básica entre envolvimento e engajamento: é totalmente possivel ser alguma coisa sem ser engajado". Para Harper e Quaye, um estudante pode estar envolvido em uma atividade ou tarefa, por exemplo, mas pouco contribuindo, interagindo ou questionando, o que o faz um aluno não engajado. Esta diferença também é evidenciada por Felicetti e Morosini (2008; 2010) quando apontam o comprometimento (engajamento) sendo muito maior que o compromisso/envolvimento, visto que o comprometimento está relacionado ao como se faz, quanto se faz e o que se faz. Em contrapartida, o compromisso se relaciona a tudo que é feito, sem considerar o que, como, quanto e quando.

De acordo com o apresentado acima acerca do comprometimento, observa-se que o mesmo não compete somente ao estudante, mas também a todos os envolvidos no contexto acadêmico. Entretanto, tal acepção seria ingênua se tomados alunos, professores e demais gestores como os únicos atores responsáveis pelo que ocorre na Educação Superior. É certo que esses atores atuam diretamente, mas também há aqueles que atuam indiretamente, definindo ou implementando leis e diretrizes a esse nível educacional. Isso evidencia a necessidade de uma dinâmica de ações capazes de identificarem e entenderem não somente os intervenientes no percurso estudantil ou os resultados de uma formação acadêmica, mas também os efeitos de leis ou diretrizes estabelecidas à Educação Superior. 
Ao se identificar e entender tais intervenientes, é possível manter o que está bem, melhorar os pontos fracos e mudar o que não está dando certo, tanto em âmbitos institucionais como aos que dizem respeito às leis ou diretrizes estabelecidas a esse nível de ensino. Nesta direção, este artigo apresenta resultados de pesquisas que evidenciam aspectos relacionados ao percurso acadêmico e resultados da graduação envolvendo tanto egressos bolsistas do Programa Universidade para Todos como não bolsistas. As evidências mostradas dizem respeito não somente ao comprometimento estudantil, mas também acerca dos resultados desse Programa.

\section{O ProUni}

O Programa Universidade para Todos foi instituído como uma Medida Provisória em 2004. Foi posteriormente convertida na Lei no 11.096, de 13 de janeiro de 2005 (Brasil, 2004; 2005). Este Programa é destinado à concessão de bolsas de estudo integrais e parciais para estudantes de cursos de graduação em instituições privadas e comunitárias de Educação Superior no Brasil. O ProUni ofereceu, de 2005 até 2014, um total de 1.296.935 bolsas integrais e 930.103 bolsas parciais, perfazendo um total de 2.227 .038 bolsas ofertadas.

A bolsa ProUni é concedida ao estudante pré-selecionado pelos resultados do Exame Nacional do Ensino Médio (ENEM) e pelo perfil socioeconômico do candidato. O ENEM é uma prova de nível nacional aplicada pelo Ministério da Educação. Com a média obtida nesse exame o candidato pode concorrer a uma vaga, tanto em instituições públicas de Educação Superior que adotam de alguma forma o ENEM, bem como em instituições privadas e comunitárias via o ProUni.

As bolsas são destinadas a brasileiros que não têm curso superior e representam semestralidades ou anuidades. As bolsas integrais são concedidas para brasileiros com renda familiar per capita mensal de até 1 (um) saláriomínimo e 1/2 (meio). As parciais são para brasileiros com renda familiar mensal per capita de até 3 (três) salários-mínimos, entre outros critérios definidos pelo Ministério da Educação. (Brasil, 2005).

O aluno contemplado necessita ter cursado integralmente o Ensino Médio em escola pública ou em instituições privadas como bolsista integral; ser portador de deficiência, nos termos da lei; ser professor da rede pública de ensino, especificamente dada para os cursos de pedagogia, licenciatura e normal superior, destinados à formação do magistério da Educação Básica, independentemente da renda acima mencionada.

O bolsista ProUni deverá ter aprovação acadêmica em, no mínimo, 75\% das disciplinas cursadas em cada período letivo para que sua bolsa seja mantida. Se o aproveitamento do aluno for insuficiente, o mesmo deverá justificá-lo junto ao coordenador do Programa Universidade para Todos em sua IES. Os alunos que têm bolsa integral não pagam pela disciplina a ser cursada pela segunda vez, já os que têm bolsa parcial pagam o percentual proporcional não coberto pela bolsa. O bolsista poderá solicitar suspensão da bolsa, porém o período suspenso será 


\section{Assensus}

considerado de efetiva utilização dentro do prazo estabelecido para a conclusão. A suspensão não pode ultrapassar três semestres, neste caso encerra-se a bolsa. A perda da bolsa ainda poderá ocorrer pela não efetivação da matrícula; pela solicitação escrita do bolsista; pelo cancelamento da matrícula; pelo insuficiente rendimento; pela evasão; pelo esgotamento do prazo máximo de conclusão; por falsidade de informação ou inidoneidade de documentos apresentados pelo bolsista; pela mudança de condição socioeconômica e pelo término do curso.

As instituições de Educação Superior, para participarem do ProUni, necessitam cumprir regras, tais como: a proporção de bolsas de estudo oferecidas por curso, turno e unidade, e também destinar um percentual a portadores de deficiência ou autodeclarados indígenas ou negros.

\section{Metodologia}

Na presente publicação, são apresentados alguns dos resultados de três projetos de pesquisa, sendo um projeto decorrente do outro em um contínuo de melhorias investigativas. No primeiro, o objetivo foi analisar o comprometimento do egresso que foi bolsista do ProUni com a sua aprendizagem, além de aspectos referentes à empregabilidade e sua satisfação com o trabalho. Os outros dois trataram de estudar o egresso da Educação Superior comparando aqueles que tiveram bolsa ProUni com os que não a tiveram, objetivando melhor entender as relações entre eles no que diz respeito às dificuldades encontradas no percurso acadêmico e os resultados da graduação. A revisão e aprimoramento do instrumento de pesquisa também foram objetivos norteadores nos projetos.

A metodologia de pesquisa usada no primeiro projeto, intitulado Comprometimento do estudante: um elo entre aprendizagem e inclusão social na qualidade da educação superior, teve abordagem mista, ou seja, tanto a qualitativa quanto a quantitativa permearam o instrumento de pesquisa. Serão apresentados aqui somente alguns resultados emergidos da análise qualitativa que se pautou na análise textual discursiva, segundo aportes de Moraes e Galiazzi (2007). Os depoimentos dos respondentes aparecerem ao longo da análise indicados pela codificação $R_{n}$, dada a cada um.

O segundo projeto, Egressos ProUni e não ProUni dos cursos de licenciatura: um estudo comparativo, e o terceiro projeto, Bolsistas ProUni e não bolsistas ingressantes no ensino superior em 2005 em uma instituição de ensino superior: onde e como estão os egressos?, tiveram abordagem apenas quantitativa. Logo, estatística descritiva e inferencial permearam a análise dos dados. As respostas foram exportadas e organizadas inicialmente na planilha Excel e, após, os dados foram importados pelo Stata/IC13.1 - Statistics/Data Analysis (Acock, 2014).

Os sujeitos participantes dos projetos de pesquisa formam egressos de três diferentes Instituições Comunitárias de Educação Superior do Rio Grande do Sul. Os convidados a responderem o instrumento de pesquisa do primeiro projeto 


\section{Assensus}

tinham que ser todos ingressantes na Instituição de Educação Superior, alvo de investigação, via concessão de bolsa ProUni em 2005 e estarem graduados no momento da pesquisa. Dos 198 graduados contatados, 134 (67,8\%) responderam ao questionário. Para o segundo projeto, todos deveriam ser ingressantes nos cursos de licenciatura na Universidade em 2005 com ou sem bolsa ProUni, dos quais 60 estavam graduados. Todos foram contatados, mas 52 $(86,7 \%)$ responderam. Já para o último, foram considerados todos os que ingressaram em 2005, independente de seu curso e de terem sido bolsistas ou não. Foi possível contatar 651, respondendo ao instrumento 197 (30,28\%).

\section{Análises em cena I: primeiro projeto}

O primeiro projeto aponta o comprometimento do estudante do ProUni como fator de superação das dificuldades encontradas no percurso acadêmico, tais como a dificuldade material versus tempo, a dificuldade geográfica e a socioafetiva. Também indica a formação acadêmica refletindo na empregabilidade e na satisfação com o trabalho.

A empregabilidade nos projetos foi considerada, de acordo com o postulado por Yorke (2006), como sendo uma característica individual e multifacetada, derivada das formas como o aluno aprende. Representa a capacidade e dedicação do egresso em realizar certa função em um determinado emprego, não devendo, portanto, ser confundida com a aquisição do emprego. Para o autor, empregabilidade não significa emprego, o qual está relacionado com a colocação, lugar ou ocupação e a função em si a ser exercida, mas sim a um conjunto de habilidades, compreensões, práticas e características individuais que tornam os egressos da Educação Superior melhor capacitados para conseguirem empregos e serem bem sucedidos na profissão escolhida. Isto beneficia a eles mesmos como também o mercado de trabalho, a sociedade e a economia.

Nesta direção, para os egressos participantes da pesquisa, estar graduado está diretamente associado ao emprego que têm. Assim sinaliza o respondente $\mathrm{R}_{64}$ : Ter uma profissão formal é poder competir mais igualitariamente no mercado de trabalho e ter a garantia de melhores possibilidades de trabalho e consequentemente melhores salários. Aqui, o respondente associa a profissão formal ao conjunto de habilidades, compreensões, e competências desenvolvido ao longo do curso como fator responsável a lhe tornar melhor preparado para o mercado de trabalho e, logo, ter melhor emprego e salário. 0 egresso $\mathrm{R}_{33}$ aponta a relação entre trabalho e formação conquistados: Hoje, aos 23 anos, no mesmo ano em que me formei, fui aprovada em primeiro lugar num concurso público, já fui chamada e tenho meu emprego garantido. Meus dois empregos me realizam muito profissionalmente e sei que só os consegui por estar formada, mérito do ProUni.

A necessidade de profissionais qualificados para o mercado de trabalho é apontada como sendo uma forma de suprir as exigências desse mercado, pois Hoje, o mercado de trabalho está cada vez mais concorrente, [...] (R1 $\left.1_{12}\right)$. Logo, a 


\section{Assensus}

associação entre empregabilidade e emprego tem que ser considerada. Para os respondentes, ser egresso da Educação Superior é ser respeitado perante as classes sociais mais favorecidas $\left(\mathrm{R}_{1}\right)$; é ter oportunidade de aprender e de ter conhecimento $\left(\mathrm{R}_{45}\right)$; é o abrir de portas tanto em relação ao conhecimento quanto em relação à cidadania. $\left(\mathrm{R}_{45}\right)$. Ainda postulam alguns egressos sobre o conhecimento: o conhecimento ninguém nunca irá me tirar! $\left(\mathrm{R} 1_{84}\right)$ e $\mathrm{R}_{112}$ Com Ensino Superior, além do ser humano sentir-se valorizado, o mesmo consegue viver dignamente, sente-se confiante e mais motivado a enfrentar as dificuldades.

A realização e a satisfação por terem estudado e conseguido se formarem em nível superior está associada, em muitos dos depoimentos ao Programa Universidade para Todos, visto que, "[...] sei que sem esse Programa, não teria condições de me formar" $\left(\mathrm{R}_{30}\right)$ e também que o "O ProUni foi um marco divisor na minha vida" $\left(\mathrm{R}_{156}\right)$. Para $\mathrm{R}_{11}$ é um Programa "que beneficia pessoas que gostariam de estudar e não possuem as condições necessárias para a formação".

Outro respondente afirma que é devido ao ProUni que ele tem uma vida digna: Foi através da vaga na faculdade que consegui meu primeiro emprego, no qual estou até hoje e, graças a ele, tenho um salário digno. Com meu salário ajudei minha mãe, que tem um restaurante. Ela emprega mais 2 pessoas. Sendo assim, minha vaga no ProUni abriu as portas para meu emprego, através do qual pelo menos mais 4 pessoas são beneficiadas indiretamente. Isso faz a economia girar. Agradeço todos os dias pela oportunidade que me foi dada. (R64).

É evidente no depoimento de $\mathrm{R}_{64}$ a relação direta e indireta entre ProUni, graduação e trabalho. Justificam-se como relação direta os benefícios conquistados pelo egresso, tal como sua remuneração. Já a relação indireta diz respeito às novas vagas de trabalho geradas pelo investimento realizado pelo graduado no negócio da mãe.

Para $R_{64}$, a concessão da bolsa ProUni fez com que ele desfrutasse 0 máximo seu tempo na universidade, em suas palavras: desfrutei o máximo que pude, me esforcei muito durante o curso, e ao final, no dia de minha formatura, fui homenageado como o melhor aluno da minha turma. Um grande orgulho para mim e para minha família. Observa-se no depoimento de $\mathrm{R}_{64}$ que estar na universidade foi para ele muito mais que ir às aulas, foi esforçar-se e aproveitar ao máximo tudo o que a universidade a ele ofereceu. Isso vai ao encontro de pesquisas que relacionam o aumento das chances de sucesso de um acadêmico ao seu comprometimento, isto é, associado ao que o estudante faz, ao como ele faz e ao quanto ele faz para melhor aprender. (Kuh, et al., 1991; Kuh, et al., 2005; Felicetti, 2011).

Para Felicetti (2011), estar na universidade é estar absorto no que ela proporciona, é empenhar-se, é estar comprometido com o aprender, com o preparar-se para as oportunidades que o mercado do trabalho e a vida podem the oferecer. Nesta direção, $\mathrm{R}_{180}$ relata: $\mathrm{Eu}$ tinha muitas tarefas, que às vezes acumulavam, pois faltava tempo para realizar tudo que era pedido. $\mathrm{E}_{103}[. .$.$] se$ dispusesse de mais tempo livre, poderia ter me dedicado ainda mais às minhas tarefas da faculdade. Eu colocava as tarefas em dia nos finais de semana [...]. 


\section{Assensus}

Observa-se nesta fala o comprometimento do estudante com a realização de suas tarefas, em extensão com a sua aprendizagem, uma vez que fazer as tarefas é parte do processo de ensino e aprendizagem.

Na realidade desses egressos ProUni, o preparar-se para o trabalho, ou seja, o estudar, acontece concomitante ao trabalhar, visto a necessidade de recursos financeiros para continuar a estudar. Trabalhar durante a faculdade foi um desafio que norteou o percurso acadêmico dos egressos e conciliar estudo e trabalho não foi tarefa simples, visto que ambos requerem dedicação. Assim, associar trabalho e tempo foi uma dificuldade enfrentada no percurso acadêmico, pois o trabalho consome o tempo, o qual seria requerido pelos estudos. $\mathrm{R}_{33}$ escreve sobre isso: A falta de tempo para maior dedicação ao estudo foi minha maior dificuldade, visto que trabalhei em turno integral (em dois empregos diferentes) durante todo o período da faculdade. Quem estuda e trabalha está correndo o tempo todo, não para e necessita fazer o tempo render. (Morato, 2009).

Fazer o tempo render muitas vezes se torna difícil por conta da distância a ser percorrida até a faculdade e o transporte necessário para tal. Nesta direção, $\mathrm{R}_{57}$ aponta que: [...] para cursar a faculdade me dirigia a outro município que fica a $45 \mathrm{~km}$ de distância. Na minha cidade não há universidades. A questão do tempo gasto no percurso, quando se depende de ônibus, pode ser considerada um tempo "perdido7". No entanto, em muitos dos testemunhos é visível ver o comprometimento com a aprendizagem, quando: Eu aproveitava o tempo lendo, mas às vezes, tem leituras tão complexas que não dá para ler no ônibus. Graças a Deus não passo mal quando leio no ônibus. ( $\left.\mathrm{R}_{88}\right)$. $\mathrm{R}_{28}$ aponta que $A$ maior dificuldade por mim enfrentada foi o percurso até a universidade, cerca de 1 hora para ir e 1 hora para voltar. E com relação ao custo. E $\mathrm{R}_{36}[. .$.$] eu gastava muito$ com passagens.

O estar na faculdade não está associado apenas com a mensalidade a ser paga, mas também a recursos financeiros necessários para alimentação, para a compra de materiais, Xerox, livros e transporte. Isto é observado em diversos depoimentos, entre eles o de $\mathrm{R}_{73}$ Eu fui bolsista [...] tive um auxílio de 300,00 reais. Tive dificuldade para me sustentar! $\mathrm{R}_{47}$ aponta as renúncias pessoais que fez para poder se manter na faculdade: [ ] não formei nova família, não viajei, não fui a festas, nunca fui exigente e, ainda assim, precisei de ajuda [...]. As renúncias feitas por $R_{47}$ representam o esforço realizado pelo egresso para manter-se na faculdade ou dar conta das exigências acadêmicas e financeiras, demonstrando comprometimento durante a graduação.

As dificuldades financeiras ainda se refletem em aspectos como o acesso à internet, computador e seus periféricos, como são indicados por $\mathrm{R}_{101}$ : Minha dificuldade foi basicamente financeira. [...] sem dinheiro, sem livros, sem um computador em casa para aproveitar os finais de semana e fazer trabalho. Ter

\footnotetext{
7 Exemplificando: parte das duas horas gastas no percurso realizado pelo egresso da fala acima, poderia ser aproveitada na biblioteca, com leituras ou pesquisas. Sem contar o desgaste físico que uma viagem proporciona. (Felicetti, 2011).
} 


\section{Assensus}

um computador ou o acesso a um parece ser algo fácil, porém, quando a remuneração é pouca, adquiri-lo se torna difícil. Não há como trocar gastos com alimentação, luz ou água pela compra de um computador ou custos com internet. Esta muitas vezes não chega à zona rural, por exemplo.

Além das dificuldades para associar o trabalho com o tempo e da questão da distância entre faculdade, residência e trabalho, há a adaptação ao meio acadêmico, o qual depende de um conjunto de fatores capazes de fazerem com que o ingressante se sinta pertencente ao contexto acadêmico. Entre esses fatores, estão as relações com colegas e professores. Os colegas não são mais os mesmos e é preciso estabelecer novas amizades. Estas, quando vão se estabelecendo, desencadeiam o início da sociabilidade, como é mencionado por $\mathrm{R}_{119}$ :

Inicialmente havia muito "preconceito" mascarado de resistência à presença de um "ser adotivo" em uma comunidade, até então, formada apenas por elites. Por mais que eu pudesse estar lá fisicamente entre eles, eu era um estranho, quer fosse pelo visual, pela linguagem, pela desenvoltura, ou pelo comportamento. Mas isso foi se desprendendo e eu fui evoluindo e percebendo a evolução dos "outros". Afinal, quem deseja aprender não se surpreende com barreiras, mas as supera.

$O$ depoimento de $\mathrm{R}_{119}$ indica o crescimento pessoal sendo desenvolvido em dois sentidos, ou seja, o dele ao ser integrado e o dos seus pares ao integrá-lo. Isso dá evidências de que ambos os lados aprendem, amadurecem e evoluem na sociabilidade, enriquecendo experiências e culturas, o que denota a possibilidade de crescer com as diferenças (Barth, 1990).

A trajetória escolar pregressa do ingressante na Educação Superior via ProUni pode também ser uma dificuldade por ele enfrentada, visto que eles são oriundos da educação pública, a qual na maioria das vezes é de baixa qualidade. Deste modo, a condição financeira já abordada não impõe apenas limites práticos como computador, mas submete limites na trajetória intelectual do acadêmico. Porém, as dificuldades apresentadas foram enfrentadas e transformadas em desafios superados ao longo do percurso acadêmico, uma vez que as dificuldades surgem para nos tornarmos mais fortes e competentes, diante de novas situações. Acredito que isto se transforma em sabedoria. $R_{45}$

\section{Análise em cena II: segundo projeto}

No segundo projeto, evidenciam-se as dificuldades no percurso acadêmico, tais como dificuldades materiais, inter-relacionais e em pré-requisitos. Também tem destaque nas análises deste projeto a relação entre a satisfação com a formação e com o trabalho conquistado. Lembra-se, aqui, que os egressos são de cursos de licenciatura8.

\footnotetext{
8 Ciências Biológicas; Computação; Educação Física; Filosofia; Física; Geografia; História; Letras; Matemática;
} Pedagogia; Química. 


\section{Assensus}

As dificuldades apresentadas pelos egressos foram organizadas em três grupos. Os percentuais correspondentes a cada grupo constam na Tabela 1. Nela pode ser observado que a maior média apresentada entre os egressos correspondeu às dificuldades materiais enfrentadas por eles com a média de 2,95, tendo os egressos ProUni a maior média, a qual foi de 3,13. Já entre os não Prounistas, a média ficou em 2,89. 0 grupo das dificuldades de pré-requisitos obteve a segunda maior média geral, que foi 2,48; para os não Prounistas, a média foi de 2,55 e 2,29 para os que foram bolsistas. Observa-se que os alunos que não foram bolsistas tiveram maiores dificuldades de pré-requisito que seus colegas bolsistas. Já entre as dificuldades inter-relacionais, os que não foram Prounistas apresentaram média maior, a qual foi de 1,77.

Tabela 1 - Dificuldades apresentadas pelos egressos durante o percurso acadêmico

\begin{tabular}{llcccc}
\hline Dificuldades & $\begin{array}{c}\text { Não ProUni } \\
\text { Média } \pm \text { d.p }\end{array}$ & $\begin{array}{c}\text { ProUni } \\
\text { Média } \pm \text { d.p }\end{array}$ & P & $\begin{array}{c}\text { TOTAL } \\
\text { Média } \pm d . p\end{array}$ \\
\hline 1- & Materiais & $2,89 \pm 1,05$ & $3,13 \pm 1,20$ & 0,49 & $2,95 \pm 1,09$ \\
2- & Interrelacionais & $1,77 \pm 0,90$ & $1,55 \pm 0,81$ & 0,42 & $1,71 \pm 0,87$ \\
3- & Pré-requisitos & $2,55 \pm 1,40$ & $2,29 \pm 1,20$ & 0,53 & $2,48 \pm 1,35$ \\
\hline
\end{tabular}

Fonte - Banco de dados formado pelas respostas dos questionários.

Na Tabela 2 pode-se identificar o percentual de satisfação com o trabalho e/ou o exercício da docência sendo este associado com trabalhar ou não na área de formação.

Destaca-se, na Tabela 2, que apenas dois egressos não se encontravam trabalhando quando da pesquisa, sendo um de cada grupo, correspondendo a $3,8 \%$ dos 52 respondentes. A opção parcialmente satisfeito obteve maior percentual tanto para os que foram bolsistas ProUni como para os que não foram e que trabalham na área de formação. Os não prounistas apresentaram o percentual de $56,5 \%$ (13) e os que foram bolsistas, 38,5\% (5). Somando tais percentuais, obtém-se $50 \%$ (18) dos que atuam na área com o grau parcialmente satisfeito com o trabalho atual. Entre os que não atuam na área e que não foram bolsistas, a opção parcialmente satisfeito teve maior percentual, o qual foi de $78,6 \%$ (11). Deste modo, o maior percentual em relação ao total de respondentes foi para a opção parcialmente satisfeito, com 57,7\% (30). Com relação às opções que envolvem algum grau de insatisfação, ou seja, parcialmente ou totalmente insatisfeito, somando ambas perfez 9,6\% em relação aos 52 egressos respondentes. Não houve significância estatística entre os grupos de egressos. 


\section{Assensus}

Tabela 2 - Satisfação com o trabalho entre egressos que trabalham e não trabalham na área

\begin{tabular}{|c|c|c|c|c|c|c|c|c|}
\hline \multirow{2}{*}{$\begin{array}{l}\text { Satisfação } \\
\text { com } \\
\text { trabalho } \\
\text { atual }\end{array}$} & \multicolumn{2}{|c|}{ Não trabalha } & \multicolumn{2}{|c|}{ Trabalha na área } & \multicolumn{3}{|c|}{ Não trabalha na área } & \multirow{2}{*}{$\begin{array}{l}\text { TOTAL } \\
\text { Fr. (\%) }\end{array}$} \\
\hline & $\begin{array}{l}\text { Não } \\
\text { ProUni } \\
\text { Fr. (\%) }\end{array}$ & $\begin{array}{l}\text { ProUni } \\
\text { Fr. (\%) }\end{array}$ & $\begin{array}{c}\text { Não ProUni } \\
\text { Fr. (\%) }\end{array}$ & $\begin{array}{l}\text { ProUni } \\
\text { Fr. (\%) }\end{array}$ & $\begin{array}{c}\text { Subtota } \\
\text { । } \\
\text { Fr. (\%) }\end{array}$ & $\begin{array}{c}\text { Não } \\
\text { ProUni } \\
\text { Fr. (\%) }\end{array}$ & $\begin{array}{l}\text { ProUni } \\
\text { Fr. (\%) }\end{array}$ & \\
\hline $\begin{array}{l}\text { Totalmente } \\
\text { satisfeito }\end{array}$ & 0 & 0 & $6(26,2)$ & $4(30,8)$ & $\begin{array}{c}10 \\
(27,8)\end{array}$ & $2(14,3)$ & 0 & $\begin{array}{c}12 \\
(23,1)\end{array}$ \\
\hline $\begin{array}{l}\text { Parcialment } \\
\text { e satisfeito }\end{array}$ & 1 & 0 & $13(56,5)$ & $5(38,5)$ & $18(50)$ & $11(78,6)$ & 0 & $\begin{array}{c}30 \\
(57,7)\end{array}$ \\
\hline $\begin{array}{c}\text { Nem } \\
\text { insatisfeito } \\
\text { nem } \\
\text { satisfeito }\end{array}$ & 0 & 1 & $1(4,3)$ & $2(15,4)$ & $3(8,3)$ & $1(7,1)$ & 0 & $5(9,6)$ \\
\hline $\begin{array}{l}\text { Parcialment } \\
\text { e } \\
\text { insatisfeito }\end{array}$ & 0 & 0 & $2(8,7)$ & $1(0,8)$ & $3(8,3)$ & 0 & 0 & $3(5,8)$ \\
\hline $\begin{array}{l}\text { Totalmente } \\
\text { insatisfeito }\end{array}$ & 0 & 0 & $1(4,3)$ & $1(0,8)$ & $2(5,6)$ & 0 & 0 & $2(3,8)$ \\
\hline TOTAL & $1(1,9)$ & $1(1,9)$ & $\begin{array}{c}23(63,9 \mathrm{e} \\
44,2)\end{array}$ & $\begin{array}{c}13(36,1 \mathrm{e} \\
25)\end{array}$ & $\begin{array}{c}36 \\
(69,2)\end{array}$ & $14(26,9)$ & 0 & $52(100)$ \\
\hline
\end{tabular}

Fonte - Banco de dados formado pelas respostas dos questionários.

\section{Análise em cena III: terceiro projeto}

Dentre os resultados emergidos no terceiro projeto, está a média das dificuldades encontradas durante o percurso acadêmico e as Médias de satisfação dos egressos, tanto prounistas como os não bolsistas, que estavam trabalhando.

Na Tabela 3 constam as médias referentes à variável "dificuldades encontradas durante o percurso acadêmico" entre os egressos do ProUni e não ProUni.

Tabela 3 - Média das dificuldades encontradas no percurso acadêmico.

\begin{tabular}{cccccc}
\hline \multirow{2}{*}{ Variável } & Fatores & Não ProUni & ProUni & & $\begin{array}{c}\text { Significância } \\
\text { da diferença }\end{array}$ \\
& & Média & Média & Diferença & $\mathbf{p ~}$ \\
\hline \multirow{2}{*}{ Dificuldades } & Trabalhar & $\mathbf{2 , 6 4}$ & 2,93 & $-0,29$ & 0,91 \\
& Financeiras & $\mathbf{2 , 2 2}$ & $\mathbf{2 , 4 4}$ & $-0,21$ & 0,85 \\
\hline
\end{tabular}


Assensus

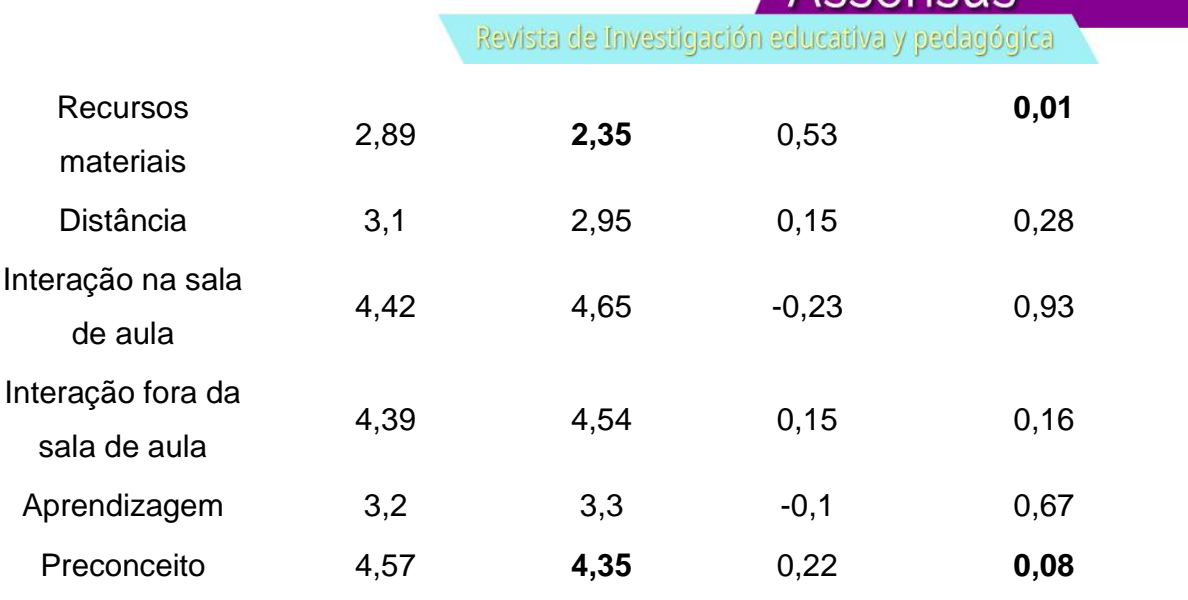

Fonte - Banco de dados formado pelas respostas dos questionários.

Também é apresentada, na Tabela 3, a diferença entre as médias em cada tipo de dificuldade, bem como o resultado do $T$-test para a significância das diferenças das médias entre ProUni ou não ProUni. Lembra-se aqui que, quanto menor a média, maior a dificuldade apresentada. A média entre as respostas corresponde a 3,0.

Como pode ser observado na Tabela 3, houve diferença estatisticamente significativa $(p=0,01)$ apenas para as médias da dificuldade "recursos materiais" (tais como ter computador, acesso à internet em casa, livros, etc.), entre ter sido ProUni, que obteve média $(2,35)$ menor, e não ProUni. Isso comprovou que os egressos ProUni teriam maior dificuldade com recursos materiais do que seus colegas não bolsistas. A dificuldade preconceito apresentou diferença estatística com indicativo de significância com $p=0,08$, na qual o grupo ProUni obteve novamente média $(4,35)$ menor, indicando maior dificuldade com o preconceito que seus colegas não bolsistas. Embora não tenha havido diferença significativa nas médias dos demais tipos de dificuldades entre os egressos, observa-se que os egressos que não foram ProUni sentiram maior dificuldade financeira do que seus colegas ProUni, bem como trabalhar durante a faculdade também apresentou maior dificuldade para eles. Ou seja, tiveram 2,22 de média para a dificuldade financeira e 2,64 para a dificuldade trabalhar durante a graduação. A interação na sala de aula também mostrou ser uma dificuldade maior entre os que não foram bolsistas, embora a média esteja próxima a 5 , o que corresponde a não concordar totalmente que este item tenha sido uma dificuldade.

A Tabela 4 apresenta a média da satisfação dos egressos com o seu trabalho atual, com o salário, com o crescimento profissional, com a formação, com as competências desenvolvidas, com os conhecimentos adquiridos no curso, com as práticas, métodos e teorias desenvolvidos pelos docentes durante o curso e com as atividades extracurriculares oferecidas pela IES na qual se graduaram. Também é apresentada nessa tabela a diferença entre as médias, bem como o nível de significância da diferença entre ser ProUni ou não ProUni pelo T-test.

Observa-se, na Tabela 4, que a média de satisfação dos egressos ProUni não é maior que a de seus colegas somente em um caso: a satisfação com o crescimento profissional. Nos demais casos, a satisfação dos prounistas apresentou-se maior. Em ambos os grupos, a maior média de satisfação está para a satisfação com a graduação, com 4,20 para os não ProUni e 4,26 entre os que 


\section{Assensus}

foram ProUni. Em seguida, encontra-se a satisfação com o trabalho, com 4,18 para o não ProUni e 4,24 para os que foram ProUni. Denota-se aqui que, para ambos os grupos, a conquista da formação e do trabalho têm um alto grau de satisfação (próximo ao valor máximo 5), evidenciando a realização de dois fatores relacionados respectivamente a necessidades intrínseca e extrínseca ao ser humano (Herzberg, et. al, 1957; Herzberg, Mausner e Snyderman, 1959; Herzberg, 1971; Herzberg, Mauser, Snyderman, 2005). As médias para os não ProUni e ProUni referente a fatores extrínsecos foi de 3,83 e 3,84 respectivamente, resultando em uma diferença de $-0,01$. A diferença entre a média dos grupos para fatores intrínsecos foi de $-0,13$, apontando a média de 3,75 de satisfação entre os não bolsistas. Esta foi menor do que a de seus pares, que foi de 3,88 . Tais achados caracterizam-se como emergentes dentro deste estudo, visto que não haviam sido traçados à priori.

Tabela 4 - Média de satisfação dos egressos não ProUni e ProUni que estavam trabalhando.

\begin{tabular}{|c|c|c|c|c|c|}
\hline \multirow[t]{2}{*}{ Variável } & \multirow[t]{2}{*}{ Fatores } & \multirow{2}{*}{$\begin{array}{c}\text { Não ProUni } \\
\text { Média }\end{array}$} & \multirow{2}{*}{$\begin{array}{l}\text { ProUni } \\
\text { Média }\end{array}$} & \multirow[b]{2}{*}{ Diferença } & \multirow{2}{*}{$\begin{array}{c}\text { Significância } \\
\text { da diferença } \\
\text { p }\end{array}$} \\
\hline & & & & & \\
\hline \multirow{12}{*}{ Satisfação } & Trabalho & 4,18 & 4,24 & $-0,06$ & 0,339 \\
\hline & Salário & 3,53 & 3,57 & $-0,04$ & 0,407 \\
\hline & Crescimento profissional & 3,78 & 3,70 & 0,08 & 0,362 \\
\hline & Fatores extrínsecos & 3,83 & 3,84 & $-0,01$ & 0,468 \\
\hline & Graduação & 4,20 & 4,26 & $-0,06$ & 0,668 \\
\hline & Competências desenvolvidas & 3,86 & 4,06 & $-0,19$ & 0,109 \\
\hline & Conhecimentos adquiridos & 3,73 & 3,89 & $-0,16$ & 0,179 \\
\hline & $\begin{array}{l}\text { Práticas desenvolvidas pelos } \\
\text { docentes }\end{array}$ & 3,74 & 3,93 & $-0,18$ & 0,138 \\
\hline & $\begin{array}{l}\text { Métodos desenvolvidos pelos } \\
\text { docentes }\end{array}$ & 3,62 & 3,76 & $-0,14$ & 0,201 \\
\hline & $\begin{array}{l}\text { Teorias desenvolvidas pelos } \\
\text { docentes }\end{array}$ & 3,78 & 3,83 & $-0,05$ & 0,379 \\
\hline & $\begin{array}{l}\text { Atividades extraclasses } \\
\text { oferecidas }\end{array}$ & 3,31 & 3,43 & $-0,12$ & 0,296 \\
\hline & Fatores intrínsecos & 3,75 & 3,88 & $-0,13$ & 0,173 \\
\hline
\end{tabular}

Fonte: Banco de dados formado pelas respostas dos questionários.

A menor média de satisfação apresentada na Tabela 4 corresponde a atividades extraclasse oferecidas pela IES para ambos os grupos, com 3,31 para os que não foram ProUni e 3,43 entre os que foram. A segunda menor média corresponde à satisfação com o salário em ambos os grupos de egressos. Não houve diferença estatisticamente significante entre os valores da variável satisfação e ser egresso ProUni ou não ProUni em nenhum dos fatores correspondentes a diferentes perspectivas de satisfação. 


\section{Assensus}

\section{Análise em cena: consistência interna do instrumento}

Com relação ao aprimoramento do instrumento de pesquisa, o mesmo contou com análise fatorial em cada instrumento aplicado. Evidenciou-se, no contínuo dos instrumentos aplicados, um avanço na consistência interna de cada grupo de questões. Assim, esse instrumento encontra consistente validação para sua aplicação no quarto projeto de pesquisa a ser desenvolvido. Na Tabela 5, constam as questões que apresentaram clusters, ou seja, as dificuldades apresentadas durante o percurso acadêmico, agrupadas em fatores externos e internos. As questões que abordavam a distância entre a faculdade e a residência ou trabalho, a aprendizagem devida à falta de pré-requisitos da Educação Básica e o trabalhar durante a realização da faculdade como sendo dificuldades apresentadas no percurso na faculdade não formaram clusters, assim não estão apresentadas na Tabela 4. Como pode ser observado, o Alpha de Cronbach encontrado para as dificuldades externas ao ambiente da faculdade foi de 0,56. É considerado, de acordo com Cronbach e Shavelson (2004), consistência interna baixa $(0,30<\alpha \leq 0,60)$. Para as dificuldades internas o Alpha de Cronbach, estas foram de 0,73. Segundo os mesmos autores supracitados, representa uma consistência interna moderada $(0,60<\alpha \leq 0,75)$. Desta forma, esses dois conjuntos de questões necessitam reformulação, contemplando questões melhor organizadas. Somente assim poderá ser aprimorada a consistência interna do conjunto de situações que podem representar dificuldades aos estudantes durante o percurso acadêmico.

Tabela 5 - Contribuição dos fatores componentes no teste Alpha de Cronbach.

\begin{tabular}{llcc}
\hline & \multicolumn{1}{c}{ Indicadores de satisfação } & \multicolumn{2}{c}{ Dimensão teórica } \\
\hline Variáveis & \multicolumn{1}{c}{ Fatores } & $\begin{array}{c}\text { Contribuição de cada fator componente } \\
\text { no teste }\end{array}$ \\
& & $\begin{array}{c}\text { Dificuldades } \\
\text { internas }\end{array}$ & $\begin{array}{c}\text { Dificuldades } \\
\text { externas }\end{array}$ \\
\hline & Financeiros & 0,3906 & $\mathbf{0 , 7 3 4 2}$ \\
Dificuldades & Recursos materiais & 0,5119 & $\mathbf{0 , 6 4 7 8}$ \\
& Interação na sala de aula & $\mathbf{0 , 8 0 1 5}$ & $-0,4113$ \\
& Interação fora da sala de aula & $\mathbf{0 , 7 9 2 1}$ & $-0,3466$ \\
\hline Consistência Interna & Preconceito & $\mathbf{0 , 6 9 0 6}$ & $-0,0205$ \\
(Alpha) & & $\mathbf{0 , 7 3}$ & $\mathbf{0 , 5 6}$ \\
\hline
\end{tabular}

Fonte - Banco de dados formado pelas respostas dos questionários.

O T-test também foi realizado após a criação das escalas para os fatores externos $(p=0,19)$ e internos $(p=0,66)$. Em ambos não houve diferença estatisticamente significativa entre ter sido bolsista ProUni ou não em relação às dificuldades apresentadas no percurso acadêmico. É possível concluir que ambos os grupos têm as mesmas dificuldades. Isso pode evidenciar que os ingressantes via ProUni passam a enfrentar os mesmos problemas que seus colegas não 


\section{Assensus}

bolsistas, o que denota que ambos os grupos necessitam de mesmo apoio e serviços para poder permanecer na faculdade e graduar-se.

Na tabela 6 encontram-se a variável satisfação e os diferentes fatores (questões) envolvendo a satisfação dos egressos. Decorrente dos achados emergentes referentes às necessidades intrínseca (motivating factors) e extrínseca (maintenance factors) dos egressos, realizou-se o Alpha de Cronbach, tabela 10. Quanto aos valores encontrados nos clusters, para os fatores extrínsecos foi de 0,82, considerado de acordo com Cronbach e Shavelson (2004) e Freitas e Rodrigues (2005) uma consistência interna alta $(0,75<\alpha \leq 0,90)$. Para os fatores intrínsecos, o Alpha de Cronbach foi de 0,91 que, segundo os mesmos autores, representa uma consistência interna muito alta.

Tabela 6 - Contribuição dos fatores componentes no teste Alpha de Cronbach.

\begin{tabular}{|c|c|c|c|}
\hline \multirow[b]{3}{*}{ Variáveis } & Indicadores de satisfação & \multicolumn{2}{|c|}{ Dimensão teórica } \\
\hline & \multirow[b]{2}{*}{ Fatores } & \multicolumn{2}{|c|}{$\begin{array}{l}\text { Contribuição de cada fator } \\
\text { componente no teste }\end{array}$} \\
\hline & & $\begin{array}{c}\text { Fatores } \\
\text { intrínsecos* } \\
\text { (motivating } \\
\text { factors) }\end{array}$ & $\begin{array}{c}\text { Fatores } \\
\text { extrínsecos }{ }^{* *} \\
\text { (maintenance } \\
\text { factors) }\end{array}$ \\
\hline \multirow{10}{*}{ Satisfação } & Com o trabalho & 0,5187 & 0,6836 \\
\hline & Com o salário & 0,4603 & 0,7244 \\
\hline & Com crescimento profissional & 0,4566 & 0,7237 \\
\hline & Com a graduação & 0,6422 & 0,0544 \\
\hline & Com as competências desenvolvidas & 0,7400 & $-0,0064$ \\
\hline & Com os conhecimentos adquiridos & 0,8173 & $-0,1867$ \\
\hline & Com as práticas desenvolvidas & 0,8278 & $-0,2670$ \\
\hline & Com os métodos desenvolvidos & 0,8627 & $-0,3135$ \\
\hline & Com as teorias desenvolvidas & 0,8180 & $-0,3046$ \\
\hline & Com atividades extraclasses & 0,7859 & $-0,1978$ \\
\hline $\begin{array}{c}\text { Consistência } \\
\text { Interna (Alpha) }\end{array}$ & & 0,91 & 0,82 \\
\hline
\end{tabular}

Fonte - Banco de dados formado pelas respostas dos questionários. ${ }^{*} p=0,83,{ }^{*} * p=0,53$

As questões foram relacionadas à teoria de Herzberg: a Two-Factor Theory (Herzberg, et. al, 1957; Herzberg, Mausner e Snyderman, 1959; Herzberg, 1971; Herzberg, Mauser, Snyderman, 2005). De acordo com essa teoria, a satisfação com o trabalho, com o salário, e com o crescimento profissional corresponde a fatores extrínsecos (maintenance factors). Já a satisfação com as competências desenvolvidas, com os conhecimentos adquiridos, com as práticas, métodos e teorias desenvolvidas durante o curso, bem como com as atividades extraclasses oferecidas aos estudantes correspondem a fatores intrínsecos. De acordo com os 


\section{Assensus}

autores supracitados, tais aspectos contemplam o desenvolvimento, o progresso e a realização da pessoa.

T-test também foi realizado após a criação das escalas para os fatores extrínsecos e intrínsecos. Em ambos, não houve diferença estatisticamente significativa entre ter sido bolsista ProUni ou não. As médias foram de 3,84 (ProUni) e 3,83 (Não ProUni) para os fatores extrínsecos com $p=0,53$. Para os intrínsecos, $o$ valor resultado foi de 3,88 para ProUni e 3,75 para não bolsistas, com $p=0,83$. Isso significa que não há uma diferença entre as respostas dos dois grupos de egressos, ou seja, o tamanho da satisfação entre os egressos tem o mesmo efeito. Portanto, ter sido ProUni ou não ProUni não evidencia maior ou menor satisfação.

\section{Conclusões}

Os resultados aqui apresentados acerca do comprometimento evidenciam que o mesmo está, de fato, relacionado com o sucesso do aluno. O sucesso, diante dos depoimentos, pode ser considerado como sendo aquilo desejado pelo estudante. Em outras palavras, ter sucesso é alcançar o que se quer para a sua vida. Em destaque, neste artigo, a meta visada é a formação em nível superior. Atrelada à conquista da formação superior estava o desejo de um emprego, um melhor salário e condições de vida. Isto era o que os respondentes desejavam e conseguiram conquistar. Como evidenciado no texto, isso não foi fácil: inúmeras dificuldades permearam o caminho, mas o comprometimento foi fator fundamental para a superação.

Muitas das dificuldades mencionadas pelos respondentes ProUni no primeiro projeto foram apontadas por um universo maior, ProUni e não ProUni, nos outros dois projetos. Os resultados apontam que as dificuldades perfazem o percurso acadêmico não somente de estudantes que foram bolsistas do Programa Universidade para Todos, mas também dos seus colegas que não tiveram o mesmo incentivo financeiro. Isso é notório tanto no segundo quanto no terceiro projeto. No segundo, não houve relação estatisticamente significante entre ter sido ou não ProUni e as dificuldades analisadas.

No terceiro projeto, embora tenha havido diferença estatisticamente significativa para a dificuldade recursos materiais entre ter sido ou não bolsista ProUni, o Teste-t aplicado no computo entre dificuldades internas e externas não se mostra significante. Isto indica que as dificuldades estão presentes nos dois grupos de participantes na mesma intensidade. Tais achados podem ser indicadores de que o ProUni coloca seus ingressantes na mesma condição que seus colegas com respeito às dificuldades encontradas no percurso acadêmico.

Sobre a satisfação dos egressos com a formação e com o trabalho conquistado, o segundo projeto aponta com maior percentual de respostas a condição parcialmente satisfeito, tanto para os bolsistas ProUni como para os não bolsistas que atuam na área de formação. O segundo maior percentual foi totalmente satisfeito. Tal resultado pode estar relacionado ao contexto atual da docência, no qual ao professorado é exigido muito mais que o ofício de professor 


\section{Assensus}

(NÓVOA, 2009). Para Nóvoa, o professor é responsabilizado por questões sociais e, muitas vezes, tem que dar conta de responsabilidades que são inerentes a outros profissionais ou até mesmo aos pais. E, embora o professor venha tentando dar conta dessas inúmeras atribuições, a profissão de professor não é valorizada no contexto brasileiro. Nesta direção, Aranha e Souza (2013, p.78) escrevem que "[...] é o baixo valor do diploma de professor, sobretudo na educação básica, tanto no mercado de bens econômicos (salário) quanto no mercado de bens simbólicos (prestígio)".

No terceiro projeto, a satisfação em relação a estar trabalhando e o trabalho ser relacionado com a formação, relacionados às variáveis: satisfação com o trabalho, com a graduação, com o desenvolvimento de competências, com o crescimento pessoal entre outras, se mostrou no mesmo patamar entre os que foram bolsistas ProUni e os que não foram. Tais resultados parecem indicar que a graduação oportuniza igualdade de oportunidades no mercado de trabalho. Isto sinaliza que aos egressos do Programa Universidade para Todos são dadas condições de competirem na conquista de novas e melhores perspectivas de vida.

Tais resultados apontam a necessidade de novos estudos. Quando se fala em pesquisa, antes de responder a questionamentos voltados ao porquê se pesquisa determinado assunto e sujeitos, ou por que se usa certa técnica de coleta ou análise de dados, necessita-se ter em mente que pesquisar é muito mais que responder objetivos. É imprescindivel uma íntima relação entre pesquisa e pesquisador, isto é, a pesquisa faz parte da vida do pesquisador e este dá vida à pesquisa, pois é sujeito partícipe no evolutivo investigativo. Isto representa dizer que pesquisa e pesquisador evoluem no ínterim investigativo, identificando que, sobre um objetivo respondido, emergem outros que requerem resposta. Logo, se amplia e aprimora o projeto, tendo em vista melhor responder tanto ao objetivo inicial quanto aos que dele emergem. Portanto, ser pesquisador é acreditar que a pesquisa não tem um ponto final. Ela tem, sim, um parágrafo inicial capaz de contribuir para com melhorias na educação e na sociedade, mesmo que tímida e lentamente.

Assim, os resultados aqui apresentados sinalizam a necessidade de maiores pesquisas referentes à temática: pesquisas capazes de ampliarem e melhor explicarem os parágrafos até então traçados; pesquisas que envolvam diferentes universidades e regiões do país e, principalmente, o apoio de governantes.

\section{Referências}

Acock, Alan C. A. (2014). Gentle Introduction to Stata, Fourth Edition, TX: Stata Press.

Aranha, Antônia Vitória Souza; Souza, João Valdir Alves De. (2013). As licenciaturas na atualidade: nova crise? Educar em Revista, Curitiba, Brasil, n. 50, p. 69-86, out./dez. Editora UFPR.

Astin, Alexander W. (1984). Student involvement: A development theory for higher education. Journal of College Student Personnel v. 25 n. 2, p. 297-308.

Barth, Robert S. (1990). A personal vision of a good school. Phi Delta Kappan, (71), 512-571. 


\section{Assensus}

Brasil. Lei no 11.096, de 13 de janeiro de 2005. Institui o Programa Universidade para Todos PROUNI, 2005. Presidência da República. Brasília, DF: Diário Oficial da União. Disponível em: <http://www.planalto.gov.br/ccivil_03/_Ato2004-2006/2005/LEl/L11096.htm > Acesso em: 19 de jun. de 2016.

Brasil. Decreto $n^{\circ}$ 6.096, de 24 de abril de 2007. Institui o Programa de Apoio a Planos de Reestruturação e Expansão das Universidades Federais - REUNI. Presidência da República. Brasília, DF: Diário Oficial da União de 25.04.2007.

Brasil. National Report of Brazil 2008. The Development of Education. Inclusive Education: The way of the future. 48th Session of the International Conference on Education Geneva Switzerland, November 25th to 28th 2008.

Brasil. (2005). Lei de Diretrizes e Bases da Educação Nacional. Brasília.

Chickering, Arthur. W.; Gamson, Zelda F. (1987). Seven Principles for Good Practice in Undergraduate Education. AAHE Bulletin, mar., p. 3-7.

Cronbach, Lee J.; Shavelson, Richard J. (2004). My Current Thoughts on Coefficient Alpha and Successor Procedures. Educational and Psychological Measurement, v.64 n.3, p.391-418.

Felicetti, Vera Lucia; Morosini, Marília Costa. (2008). O Comprometimento do Estudante com a Aprendizagem - Onde está o Estado da Arte. In. ANPEDSUL - VII Seminário de Pesquisa em Educação da Região Sul. Pesquisa em educação e inserção social. Itajaí: Univali.

Felicetti, Vera Lucia; MOROSINI, Marília Costa. (2009). Equidade e iniquidade no ensino superior: uma reflexão. Ensaio: Avaliação e Políticas Públicas em Educação, Rio de Janeiro, v. 17, n. 62, p. 9-24.

Felicetti, Vera L. (2011). Comprometimento do estudante: um elo entre aprendizagem e inclusão social na qualidade da educação superior. 2011. 298 f. Tese (Doutorado em Educação) - Pontifícia Universidade do Rio Grande do Sul, Rio Grande do Sul.

Harper, Shaun R.; Quaye, Stephen John. (2009). Student Engagement in Higher Education: theoretical perspectives and practical approaches for diverse populations. New York: Routledge.

Herzberg, Frederick. (1971). Work and the nature of man. New York: World Publishing.

Herzberg, Frederick; Mausner, Bernard; Snyderman, Barbara B. (1959). The Motivation to Work (2nd ed.). New York: John Wiley.

Herzberg, Frederick; Mausner, Bernard; Snyderman, Barbara Bloch. (2005). The motivation to work. New Jersey: Transaction Publishers.

Herzberg, Frederick; Mausner, Bernard; Peterson, Richard O. e Capwell, Dora. (1957) Job attitudes: Review of research and opinion. Pittsburgh, PA: Psychological Service of Pittsburgh.

Kuh, George. D.; Schuh, J. H.; Whitt, E. J. (1991). Associates. Involving Colleges: Successful Approaches to Fostering Student Learning and Personal Development Outside the Classroom. San Francisco: Jossey-Bass,.

Kuh, George D., et al. (2005). Assessing Conditions to Enhance Educational Effectiveness: The Inventory for Student Engagement and Success. San Francisco: Jossey-Bass.

Moraes, Roque; Galiazzi, Maria do Carmo. (2007). Análise textual discursiva. ljuí: Unijuí.

Morato, Cíntia Thais. (2009.) Estudar e trabalhar durante a graduação em Música: construindo sentidos sobre a formação profissional do músico e do professor de música. Tese de Doutorado, Universidade Federal do Rio Grande do Sul, Porto Alegre.

Nóvoa, Antonio. (2009). Professores: imagens do futuro presente. Lisboa: Educa. 


\section{Assensus}

Pace, Charles Robert. (1979). The Other Side of Accountability: Measuring Students' Use of Facilities and Opportunities. AIR Forum 1979 Paper. Speeches/Meeting Papers; Reports Research, $1979 . \quad$ Disponível em: <http://www.eric.ed.gov/ERICWebPortal/Home.portal?_nfpb=true\&ERICExtSearch_SearchValue_ $0=$ robert+pace\&ERICExtSearch_SearchType_0=kw\&_pageLabel=ERICSearchResult $>$ Acesso em: 07 de jun. 2016.

Pace, Charles Robert. (1981). Measuring the Quality of Undergraduate Education. Reports Research; Speeches/Meeting Papers. Disponivel em: <http://www.eric.ed.gov/ERICWebPortal/Home.portal?_nfpb=true\&ERICExtSearch_SearchValue_ 0=robert+pace\&ERICExtSearch_SearchType_0=kw\&_pageLabel=ERICSearchResult >Acesso em 07 de jun. 2016.

Pace, Charles Robert. (1982). Achievement and the Quality of Student Effort. National Commission on Excellence in Education (ED). Washington, DC. Disponível em: <http://www.eric.ed.gov/ERICWebPortal/Home.portal?_nfpb=true\&ERICExtSearch_SearchValue_ $0=$ robert+pace\&searchtype=basic\&ERICExtSearch_SearchType_0=kw\&pageSize=10\&eric_displa yNtriever=false\&eric_displayStartCount=91\&_pageLabel=RecordDetails\&objectld=0900019b80 047798\&accno=ED227101\&_nfls=false> Acesso em 07 de jun. 2016.

Pace, Charles Robert. (1984). Measuring the quality of college student experiences. Higher Educational Research Institute, Graduate School of Education, University of California.

Tinto, Vincent. (1987). Leaving College: Rethinking the Causes and Cures of Student Attrition. Chicago: University of Chicago Press.

Tyler, Ralph Winfred. (1949). Basic Principles of Curriculum and Instruction. Chicago: University of Chicago Press.

Yorke, Mantz (2006). Employability in higher education: what it is - what it is not. Learning \& Employability. Series one. London. 